\title{
miR-142-3p Suppresses Cell Growth by Targeting CDK4 in Colorectal Cancer
}

\author{
Xiangyu Zhu ${ }^{a}$ Si-ping Ma ${ }^{a}$ Dongxiang Yang ${ }^{b}$ Yanlong Liuc Yong-peng Wang ${ }^{\mathrm{a}}$ \\ Tao Lin ${ }^{a} \quad$ Yan-xi Li ${ }^{a} \quad$ Shi-hua Yang ${ }^{a}$ Wan-chuan Zhanga ${ }^{a}$ Xin-ling Wang ${ }^{d}$ \\ aDepartment of Colorectal Surgery, Cancer Hospital of China Medical University, Liaoning Cancer \\ Hospital \& Insititute, Liaoning, ${ }^{b}$ Department of Orthopedics, The Affiliated Hospital of Liaoning \\ University of Traditional Chinese Medicine, Liaoning, 'Department of Colorectal Surgery, Harbin \\ Medical University Cancer Hospital, Heilongjiang, dDepartment of Ophthalmology, the Fourth Affiliated \\ Hospital, China Medical University, Liaoning, China
}

\section{Key Words}

Colorectal cancer $\cdot \mathrm{miR}-142-3 p \cdot \mathrm{CDK} 4 \cdot$ Cell cycle

\begin{abstract}
Background/Aims: Deregulation of microRNAs (miRNAs) has been associated with a variety of cancers, including colorectal cancer (CRC). Here, we investigated anomalous miR-142$3 p$ expression and its possible functional consequences in primary CRC samples. Methods: The expression of miR-142-3p was measured by quantitative RT-PCR in 116 primary CRC tissues and adjacent non-tumor tissues. The effect of miR-142-3p up- or down-regulation in CRC-derived cells was evaluated in vitro by cell viability and colony formation assays and in vivo by growth assays in xenografted nude mice. Results: Using quantitative RT-PCR, we found that miR-142-3p was down-regulated in $78.4 \%$ (91/116) of the primary CRC tissues tested when compared to the adjacent non-tumor tissues. We also found that the miR-142$3 p$ mimic reduced in vitro cell viability and colony formation by inducing cell cycle arrest in CRC-derived cells, and inhibited in vivo tumor cell growth in xenografted nude mice. Inversely, we found that the miR-142-3p inhibitor increased the viability and colony forming capacity of CRC-derived cells and tumor cell growth in xenografted nude mice. In addition, we identified CDK4 as a potential target of miR-142-3p by predictions and dual-luciferase reporter assays. Concordantly, we found that miR-142-3p mimics and inhibitors could decrease and increase CDK4 protein levels in CRC-derived cells, respectively. Conclusion: From our results we conclude that miR-142-3p may act as a tumor suppressor in CRC and may serve as a tool for miRNA-based CRC therapy.




\section{Cellular Physiology Cell Physiol Biochem 2018;51:1969-1981

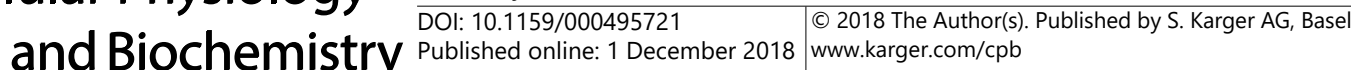 \\ Zhang et al.: miR-142-3p Targeting CDK4 in CRC}

\section{Introduction}

Colorectal cancer (CRC) is one of the leading causes of death worldwide [1]. Development of CRC is a stepwise process comprising genetic changes in tumor-suppressor genes in most of the cases. In addition, a multitude of molecular alterations of genes have been described in the literature as being associated with development and prognosis of CRC [2]. However, the mechanisms that drive the process of neoplastic transformation are not well understood. Thus, there is an urgent need to elucidate the underlying molecular mechanisms of CRC and find new molecular targets for treatment against this disease.

MiRNAs are endogenous non-coding 20-22 nucleotide long RNAs that may act as posttranscriptional regulators of gene expression [3]. They regulate gene expression at the transcriptional and post-transcriptional level by completely or incompletely binding to the 3'-UTR of their target gene messenger RNA (mRNA) and by repressing the translation or promoting the degradation of the tar-get gene to exert biological functions [4, 5]. MiRNA expression deregulation has been observed in a wide range of human diseases, including cancer [4], and it has been shown that this deregulation may play a pivotal role in processes such as cellular differentiation, proliferation, angiogenesis, apoptosis and invasion [5]. To date, deregulated miRNAs and their roles in CRC development have attracted much attention. A series of miRNAs have been reported that miR-19 [6], miR-140-5p [7], miR-149 [8], miR153[9], miR-195-5p [10] and miR-301 $\alpha$ [11], play important roles in the development of CRC.

Recently, we indentified several significantly deregulated miRNAs in CRC, including miR138, miR-206, miR-214, miR-498 and miR-142-3p, using a miRNA expression microarray approach (unpublished data). Most of theses miRNAs have previously been reported to be involved in several types of cancers, including CRC [12-16]. In the present study, we investigated the role of miR-142-3p in CRC. Our results showed that the expression of miR142-3p was down-regulated in CRC tumor tissues compared to paired adjacent non-tumor tissues. Moreover, in vitro experiments proved that miR-142-3p inhibited cell proliferation in the CRC cell lines. In addition, CDk4 was identified as a novel direct target gene of miR142-3p. Our findings suggested that miR-142-3p has a tumor suppressive effect in CRC by inhibiting cell proliferation.

\section{Materials and Methods}

\section{Human tissue specimens}

Fifty six pairs of human CRC and adjacent nontumor tissue samples were obtained immediately after resection from patients undergoing primary surgical treatment in Department of colorectal surgery, Cancer Hospital of China Medical University, LiaoNing, China. None of the patients had undergone preoperative irradiation or chemotherapy. The tissue samples were frozen in liquid nitrogen and stored at $-80^{\circ} \mathrm{C}$ until use. The tissue samples were obtained from 86 male and 30 female patients (Average age: 63.2 years; range: 53 to 68 years) and their clinicopathological features are listed in Table 1. Written consent for research purposes was obtained from the patients before tissue collection and the protocol was approved by the Institutional Review Board of China Medical University.
Table 1. The data of patients $(n=116) .{ }^{*}$ Diameter of the biggest nodule, ${ }^{* *}$ TNM: tumor-nodemetastasis

\begin{tabular}{|c|c|}
\hline Variable & Value \\
\hline Age(years) & $63.2 \pm 10.1$ \\
\hline Gender(male) & $86(74.1 \%)$ \\
\hline Tumor size $(\mathrm{cm})$ & 5.46 \\
\hline \multicolumn{2}{|l|}{ Tumor grade } \\
\hline Well-differentiated (G1-2) & 53 \\
\hline Moderately-differentiated (G3) & 51 \\
\hline Poorly-differentiated (G4) & 12 \\
\hline \multicolumn{2}{|l|}{ TNM stage $^{* *}$} \\
\hline I & 31 \\
\hline II & 37 \\
\hline III & 36 \\
\hline IV & 12 \\
\hline
\end{tabular}




\section{Cellular Physiology Cell Physiol Biochem 2018;51:1969-1981 and Biochemistry \begin{tabular}{l|l} 
DOI: 10.1159/000495721 & $\begin{array}{l}\text { C } 2018 \text { The Author(s). Published by S. Karger AG, Basel } \\
\text { www.karger.com/cpb }\end{array}$
\end{tabular} \\ Zhang et al.: miR-142-3p Targeting CDK4 in CRC}

Cell cultures

The human embryonic kidney-derived cell line HEK293T and the human CRC-derived cell lines HT29 and SW116 were maintained in Dulbecco's modified eagle's medium (DMEM, Hyclone, Thermo Fisher Scientific, Waltham, MA, USA) supplemented with $100 \mathrm{U}$ penicillin/ml, $100 \mathrm{mg}$ streptomycin/ml and $10 \%$ fetal bovine serum (FBS, Gibco) at $37^{\circ} \mathrm{C}$ in a humidified atmosphere of $5 \% \mathrm{CO}_{2}$.

\section{Transfections}

The transfections were carried out using the FuGene HD transfection reagent (Roche, Indianapolis, IN, USA) according to the manufacturer's protocol. In brief, $2 \times 10^{4}$ HT29 and SW116 cells or $5 \times 10^{4}$ HEK293T cells, seeded in 24-well plates, were transfected with the indicated plasmid DNAs, miRNA duplexes (GenePharma, Shanghai, China) or siRNAs (GenePharma) and collected 24-48 hours after transfection for further assessment.

\section{Quantitative real time PCR}

cDNA synthesis and qRT-PCR-based miRNA expression analyses were carried out using TaqMan microRNA assay kits (Applied Biosystems) according to the manufacturer's protocol. Briefly, total RNA was extracted using TRIzol Reagent (Invitrogen) from the clinical samples or CRC-derived cell lines, and used to synthesize cDNA with gene-specific primers. Reverse transcription reactions were carried out using $100 \mathrm{ng}$ RNA, $50 \mathrm{nM} / \mathrm{L}$ stem-loop RT primers, $1 \times$ RT buffer, $0.25 \mathrm{mM} / \mathrm{L}$ of each dNTP, $3.33 \mathrm{U} / \mu$ l MultiScribe reverse transcriptase and $0.25 \mathrm{U} / \mu \mathrm{l}$ RNase inhibitor. $15 \mu \mathrm{l}$ mixtures were incubated for $30 \mathrm{~min}$ at $16^{\circ} \mathrm{C}, 30 \mathrm{~min}$ at $42^{\circ} \mathrm{C}, 5 \mathrm{~min}$ at $85^{\circ} \mathrm{C}$, and then held at $4^{\circ} \mathrm{C}$. The resulting cDNA product was subsequently used for qRT-PCR analysis. The PCR reaction mixtures $(20 \mu \mathrm{l})$ included $1.33 \mu \mathrm{l}$ RT product, $1 \times$ TaqMan universal PCR master mix and $1 \mu \mathrm{l}$ primers and probe mix from the TaqMan microRNA assay kit. The reaction mixtures were incubated in 96 -well optical plates at $95^{\circ} \mathrm{C}$ for $5 \mathrm{~min}$, followed by 40 cycles at $95^{\circ} \mathrm{C}$ for $15 \mathrm{sec}$ and $60^{\circ} \mathrm{C}$ for $1 \mathrm{~min}$. The PCR reactions were run on a StepOne Plus real time PCR machine (Applied Biosystems) and the data were analyzed using SDS v2.3 software. The Ct value was defined as the fractional cycle number at which the fluorescence passed a fixed threshold. The fold change was calculated using the $2^{-\Delta \Delta C t}$ method and presented as the fold-expression change in tumor tissues relative to their corresponding non-tumor tissues after normalization to the endogenous control.

\section{Luciferase reporter constructs}

The 3'-UTR fragment of CDK4 (Genbank accession no. NM_000075) containing the putative miR-142-3p binding sequence (1334-1344nt) was amplified using the primers 5'-GGCTGCCATGGAAGGAAGAAAAGC-3' (forward) and 5'-GTCTTGCTCTGTTGCCCAGGCTGGAG-3' (reverse). The resulting PCR product was cloned into a firefly luciferase reporter vector (pGL3; Promega Corporation, Madison, WI, USA), and termed pGL3CDK4-3'UTR. A plasmid that carried mutations in the complementary sites for the seed region of miR-142-3p was generated based on the pGL3-CDK4-3'UTR plasmid using a MutanBEST Kit (Takara Bio Inc., Shiga, JP), and termed pGL3-CDK4-3'UTR-mut. The correctness of the plasmids was confirmed by sequence analysis.

\section{Cell viability and colony formation assays}

Twenty four hours after transfection, 1000 HT29 or SW116 cells were seeded in fresh 96-well plates in triplicate and maintained in DMEM containing 10\% FBS for 5 days. Next, the cells were tested for proliferation per 24 hours using a Cell Titer-Blue cell viability assay (Promega Corporation, Madison, WI, USA) according to the manufacturer's instructions, and the fluorescence ratios were recorded using a multiplate reader (Synergy 2, BioTek, Winooski, VT, USA). Additionally, 24 hours after transfection, 2000 HT29 or SW116 cells were seeded in fresh 6-well plates in triplicate and maintained in DMEM containing 10\% FBS for 2 weeks. Next, cell colonies were fixed in $20 \%$ methanol and stained with $0.1 \%$ coomassie brilliant blue R250 at room temperature for 15 min. Finally, the colonies were counted using an ELIspot Bioreader 5000 (BIO-SYS, Karben, GE). 


\section{Cellular Physiology Cell Physiol Biochem 2018;51:1969-1981 \begin{tabular}{ll|l} 
and Biochemistry & $\begin{array}{l}\text { DOI: 10.1159/000495721 } \\
\text { Published online: 1 December } 2018\end{array}$ & $\begin{array}{l}\text { (c) } 2018 \text { The Author(s). Published by S. Karger AG, Basel } \\
\text { www.karger.com/cpb }\end{array}$
\end{tabular}

\section{Cell cycle and apoptosis assays}

Forty eight hours after transfection, $1 \times 10^{5}$ HT29 and SW116 cells were harvested, washed once in phosphate buffer saline (PBS), and fixed in $70 \%$ ethanol at $4^{\circ} \mathrm{C}$ overnight. Next, DNA staining was performed with $50 \mathrm{mg} / \mathrm{ml}$ propidium iodide and $1 \mathrm{mg} / \mathrm{ml} \mathrm{RNase} A$ at room temperature for $30 \mathrm{~min}$. The cell populations in the G0-G1, S and G2-M phases of the cell cycle were measured using Cell Lab Quanta SC flow cytometry (Beckman Coulter, Fullerton, CA, USA) and the data were analyzed using the FlowJo v7.6 software package.

Tumorigenicity assays in nude mice

Male BALB/c nude mice (5-6 weeks old) were obtained from the ShenYang Experimental Animal Center (ShenYang, China). All animal handling and experimental procedures were approved by the Animal Experiments Ethics Committee of the China Medical University. For the in vivo tumorigenicity assays, all pyrimidine nucleotides in the miR-142-3p mimic, miR-142-3p inhibitor or the NC duplex were substituted by their 2'-0-methyl analogues to improve the RNA stability. MiR-142-3p mimic or miR-142-3p inhibitor transfected HT29 cells $\left(1 \times 10^{6}\right)$ were suspended in $100 \mu \mathrm{l}$ PBS and injected subcutaneously into left side of the posterior flank of $6 \mathrm{BALB} / \mathrm{c}$ nude mice, respectively. Nonrelated control (NC) transfected or nontransfected HT29 cells $\left(1 \times 10^{5}\right)$ were injected subcutaneously into right side of same 12 mice. Tumor growth was examined daily and the tumor volumes were calculated every week using the formula for hemiellipsoids: $V=$ length $(\mathrm{cm}) \times$ width $(\mathrm{cm}) \times$ height $(\mathrm{cm}) \times 0.5236$. After 5 weeks, the mice were sacrificed and the tumors were dissected and photographed.

\section{Dual-luciferase reporter assay}

HEK293T cells, seeded in 24-well plates in triplicate, were co-transfected with pGL3-CDK4-3'UTR or pGL3-CDK4-3'UTR-mut and the miR-142-3p mimic or nonrelated control RNA duplex (NC duplex, GenePharma) using the FuGene HD transfection reagent. The pRL-TK construct (Promega Corporation, Madison, WI, USA) was also transfected as a normalization control. The cells were collected $48 \mathrm{hrs}$ after transfection, and luciferase activity was measured using a dual-luciferase reporter assay kit (Promega Corporation) and recorded using the multi-plate reader (Synergy 2, BioTek).

\section{Western blotting}

Total protein was extracted using a modified RIPA buffer with 0.5\% SDS and the proteinase inhibitor cocktail (Complete Mini, Roche). Equal amounts of protein from CRC tissues and their adjacent non-tumor tissues were electrophoresed in 10\% SDS-PAGE mini gels and transferred to PVDF membranes (Immobilon $\mathrm{P}^{-\mathrm{SQ}}$, Millipore, Billerica, MA, USA). After blocking with 5\% nonfat milk, the membranes were incubated with the rabbit anti-CDK4 antibody (1:1000 dilution, Epitomics, Inc., Burlingame, CA, USA) or mouse anti-GAPDH antibody (1:5000 dilution, Epitomics, Inc.) at $4^{\circ} \mathrm{C}$ overnight, followed by incubation with HRP-conjugated goat anti-rabbit or goat anti-mouse antibody (1:10000 dilution, KPL, Gaithersburg, MA,USA) for $1 \mathrm{hr}$ at room temperature. Finally, signals were developed using Super Signal West Pico chemoluminescent substrate (Pierce, Rockford, Ill, USA), visualized by the Gene Gnome HR Image Capture System (Syngene, Frederick, MD, USA) and analyzed by Gene tools (Syngene).

\section{miRNA target prediction}

MiRanda (www.microrna.org) was used to predict miRNA targets and conserved sites bound by the seed region of miR-142-3p.

\section{Statistical analysis}

Data are presented as mean \pm SD. Comparisons were made by using a two-tailed t test or one-way ANOVA for experiments with more than two subgroups. Correlation analyses were performed using Spearman correlation coefficient. $\mathrm{P}<0.01$ was considered statistically significant. Associations between miR-142-3p expression and cancer-specific survival rates were assessed using the Kaplan-Meier method. 


\section{Results}

miR-142-3p is downregulated in $C R C$

To investigate the relevance of miR-142-3p in CRC, we first set out to measure its expression in 18 pairs of tumor versus adjacent non-tumor tissues by qRT-PCR. miR-142-3p was found to be down-regulated in more than $70 \%$ of the tumor tissues compared to the nontumor tissues tested (Fig. 1A). To validate these initial qRTPCR data, the expression of miR-142-3p was measured in another series of 38 paired CRC tissues. Again, mR-613 showed a significant down-regulation in the tumor tissues compared to the adjacent non-tumor tissues (116 pairs in total, Fig. 1B). In addition, we found that patients whose primary tumors did not exhibit miR-142-3p down-regulation showed a trend towards a better survival (Fig. 1C). The mean survival in the poor survival group was 57.4 months (low miR-142-3p expression, $\mathrm{n}=82$ ), whereas the mean survival in the better survival group was 93.8 months (high miR-142-3pexpression, $\mathrm{n}=34$ ). No statistical significant correlations were observed between miR-142$3 p$ expression and the other clinicopathological features tested (age, sex, stage and tumor size; data not shown).

miR-142-3p induces cell cycle arrest

The significant reduction in miR-142-3p expression observed in the primary tumor tissues versus the non-tumor tissues suggests a possible role in CRC development. To test this hypothesis, we first set out to assess the effect of miR-142-3p on the growth of HT29 and SW116 CRC-derived cells transfected or not with the miR-142-3p mimic, miR-142-3p inhibitor or NC duplex. We found that the expression of miR-142-3p was increased 27.5-fold (HT29) and 26.0-fold (SW116) in cells transfected with $20 \mathrm{nM}$ miR-142-3p mimic, and was deceased 32.5-fold (HT29) and

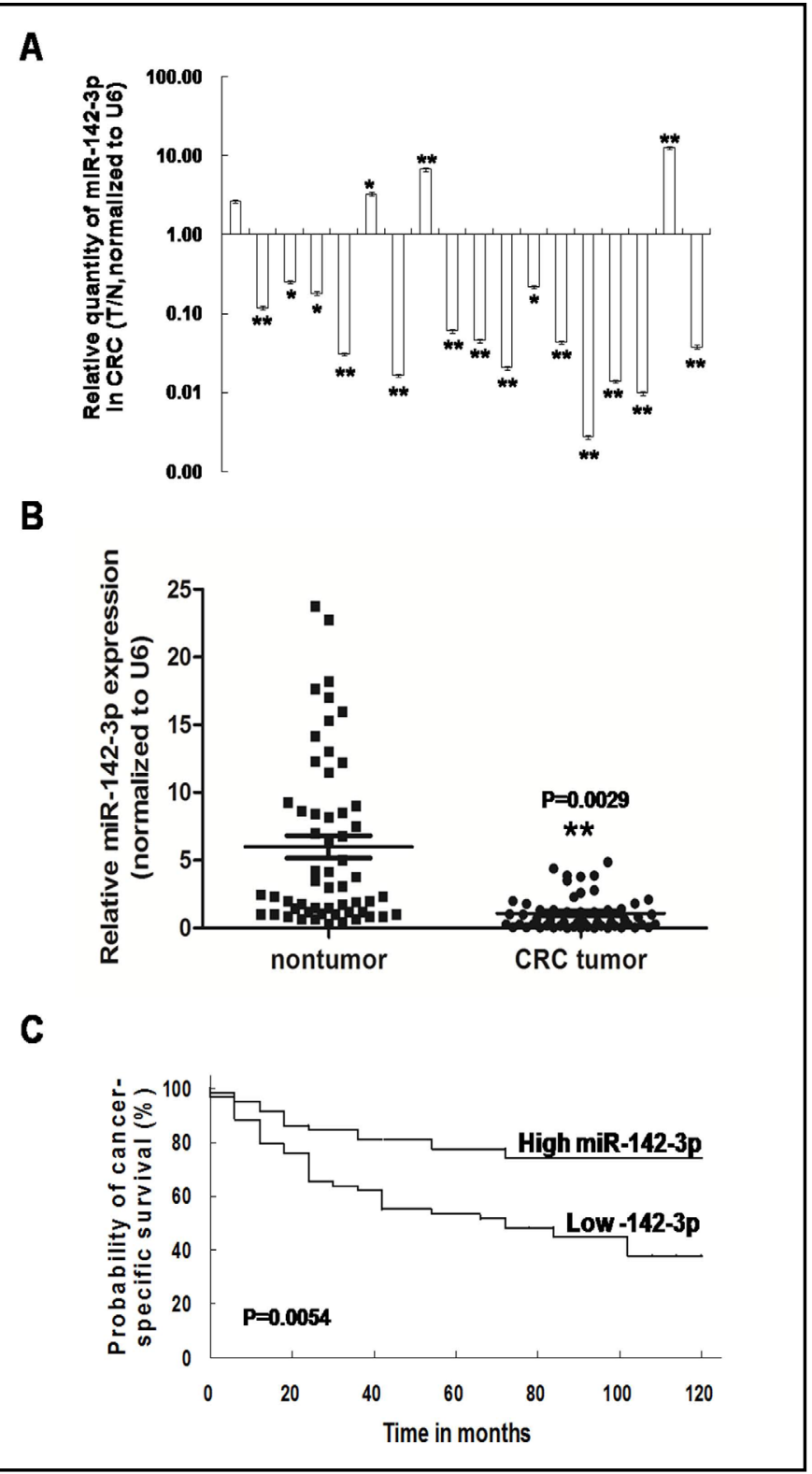

Fig. 1. MiR-142-3p is downregulated in CRC. A. Expression of miR-142-3p in 18 CRC tumor tissues (T) and adjacent non-tumor tissues (N). B. Expression of miR-142-3p in 116 CRC tumor tissues (T) and adjacent non-tumortissues $(\mathrm{N})$. The fold change was calculated using the $2^{-\Delta \Delta C t}$ method and presented as the foldexpression change in tumor tissues ( $\mathrm{T}$ ) relative to their adjacent non-tumor tissues $(\mathrm{N})$ after normalization to the endogenous control (U6). ${ }^{*} \mathrm{P}<0.05$; ${ }^{* *} \mathrm{P}<0.01$. C. Probability of cancer-specific survival by miR-142-3p expression levels in CRC. 


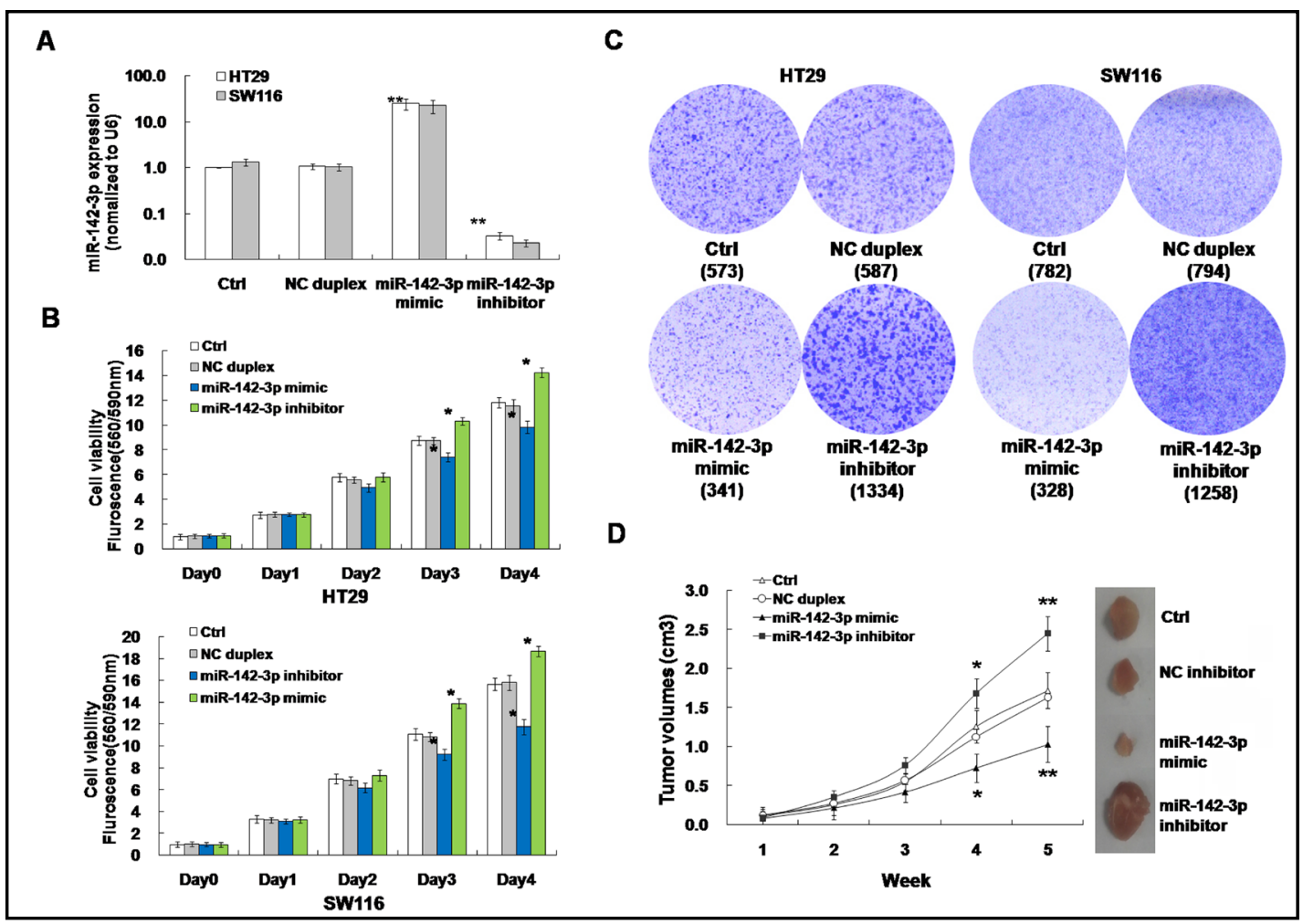

Fig. 2. MiR-142-3p suppresses cellular growth. A. Expression of miR-142-3p in HT29 and SW116 cells after transfection with miR-142-3p mimic, miR-142-3p inhibitor or NC duplex. B. Effect of miR-142-3p on the viability of CRC-derived cells. C. Effect of miR-142-3p on colony formation of CRC-derived cells. D. Effect of miR-142-3p on tumor growth in xenografted nude mice. Representative results (B-D) of HT29 and SW116 cells transfected with miR-142-3p mimic, miR-142-3p inhibitor or NC deplex. Columns, means of three independent experiments; bars, $\pm \mathrm{SD} ;{ }^{*} \mathrm{P}<0.01{ }^{* *} \mathrm{P}<0.001$.

41.5-fold (SW116) in cells transfected with $20 \mathrm{nM} \mathrm{miR-142-3p} \mathrm{inhibitor} \mathrm{(Fig.} \mathrm{2A).} \mathrm{From} \mathrm{day}$ 2 (HT29) or day 3 (SW116) onwards after transfection, the viability of the cells transfected with the miR-142-3p mimic significantly decreased compared to that of the NC duplex transfected or non-transfected cells, whereas the viability of the cells transfected with the miR-142-3p inhibitor significantly increased (Fig. 2B). These results indicate miR-142-3p can inhibit the growth of CRC-derived cells.

To validate the inhibitory effect of miR-142-3p on cellular growth, colony forming assays were performed on HT29 and SW116 cells transfected or not with the miR-142$3 p$ mimic, miR-142-3p inhibitor or NC duplex. As shown in Fig. 2C, HT29 and SW116 cells transfected with $20 \mathrm{nM}$ miR-142-3p mimic exhibited fewer and smaller colonies (341 and 328 colonies, respectively) compared to the NC duplex transfected (587 and 794 colonies, respectively) and non-transfected cells (573 and 782 colonies, respectively), whereas cells transfected with $20 \mathrm{nM}$ miR-142-3p inhibitor exhibited more and larger colonies (1334 and 1258 colonies, respectively).

To further confirm the above findings, an in vivo mouse model was used. After treatment with the miR-142-3p mimic or miR-142-3p inhibitor for 5 weeks, the tumor volume curves revealed significant decreases in growth rates during the 3rd, 4th and 5th weeks after treatment with the miR-142-3p mimic and significant increases in growth rates during the 4 th and 5th weeks after treatment with the miR-142-3p inhibitor, whereas no significant differences in growth rates were observed in the NC group and the non-transfected control group (Fig. 2D). These results indicate that miR-142-3p significantly inhibits the growth of CRC-derived HT29 cells in the xenograft mouse model. 
To investigate the mechanism underlying the growth inhibitory effect of miR142-3p, flow cytometry was carried out. We found that the percentages of the miR-142-3p mimic transfected HT29 and SW116 cells in the G0-G1 phase were $17.5 \%$ (HT29) and $13.2 \%$ (SW116) higher than that of the NC duplex transfected or nontransfected cells, which coincided with a $42.3 \%$ (HT29) and a $36.5 \%$ (SW116) decrease in $\mathrm{S}$ phase cells (Fig. 3A). In the miR-142$3 p$ inhibitor transfected cells, the percentages of cells in the G0-G1 phase were 9.6\% (HT29) and $7.4 \%$ (SW116) lower than that of the NC duplex transfected or non-transfected cells, which coincided with a $15.2 \%$ (HT29) and a $18.6 \%$ (SW116) increase in $S$ phase cells (Fig. 3B). These results indicate that miR-142-3p may inhibit CRC-derived HT29 and SW116 proliferation by inducing cell cycle arrest in the G1/S phase.

CDK4 is a direct target of miR-142-3p

It is generally accepted that miRNAs may exert their functions through regulating the expression of downstream target genes. CDK4 was predicted to be a potential target of miR-142-3p by TargetScan and PicTar, since the 3'-UTR of the CDK4 mRNA contains a complementary site for the seed region of miR-142$3 p$ (Fig. 4A). To validate whether CDK4 acts as a direct target of miR-142-3p, human CDK4 3'UTR fragments containing wildtype or mutant miR-142-3p binding sequences (Fig. 4A) were cloned downstream of the firefly luciferase reporter gene in pGL3.

In HEK293 cells co-transfected with the reporter plasmids and the miR-142-3p mimic or NC duplex, the luciferase activity of the reporter that contained the wild-type 3'-UTR was found to be significantly suppressed by the miR-142-3p mimic, whereas the luciferase activity of the mutant reporter was unaffected (Fig. 4B), indicating that miR-142-3p may suppress CDK4

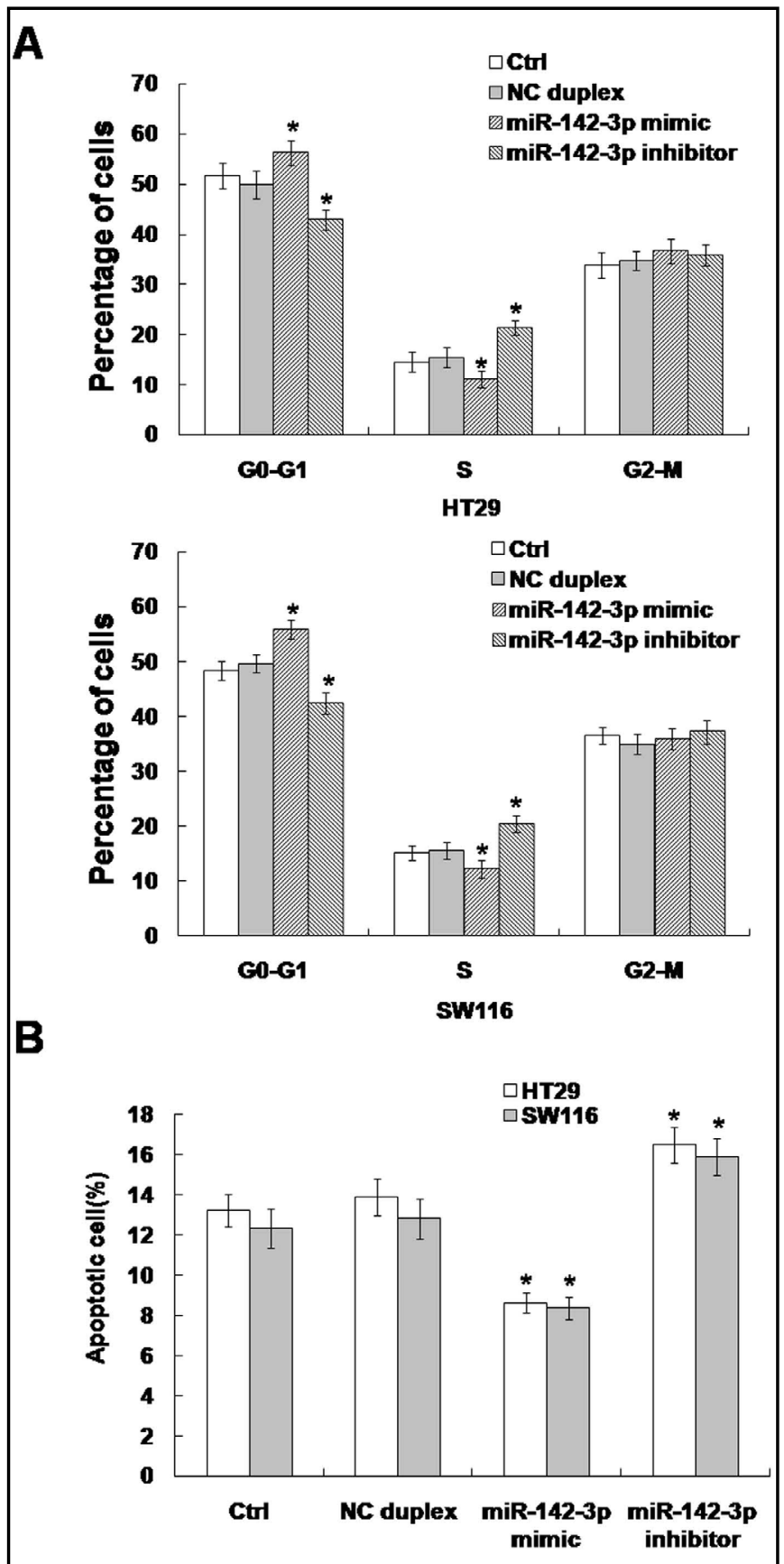

Fig. 3. miR-142-3p induces cell cycle arrest and enhances cell apoptosis. A. Effect of miR-142-3p on the cell cycle. B. Effect of miR-142-3p on apoptosis. Representative results of HT29 and SW116 cells transfected with miR-142-3p mimic, miR-142-3p inhibitor, NC duplex. Columns, means of three independent experiments; bars, $\pm \mathrm{SD} ;{ }^{*} \mathrm{P}<0.01$; ${ }^{* *} \mathrm{P}<0.001$. 
Fig. 4. CDK4 is a direct target of miR142-3p. A. Putative miR-142-3p binding sequence in the 3'-UTR of CDK4 mRNA. The mutation was generated in the CDK4 3 '-UTR sequence in the complementary site of the miR-142-3p seed region. B. Suppressed luciferase activity of wildtype CDK4 3'UTR by miR-142-3p mimic. HEK293T cells were co-transfected with pGL3-CDK4-3'UTR or pGL3-CDK4-3'UTRmut, and miR-142-3p mimic or NC duplex. Firefly luciferase activity of each sample was measured $48 \mathrm{~h}$ after transfection and normalized to Renilla luciferase activity. C. Expression of endogenous CDK4 is regulated by miR-142-3p. The expression level of endogenous CDK4 in HT29 cells was assessed $48 \mathrm{~h}$ after transfection with miR-142-3p mimic, miR-142-3p inhibitor or NC duplex by Western blotting. GAPDH was used as an internal control. Columns, means of three independent experiments; bars, $\pm \mathrm{SD} ;{ }^{*} \mathrm{P}<0.01$.

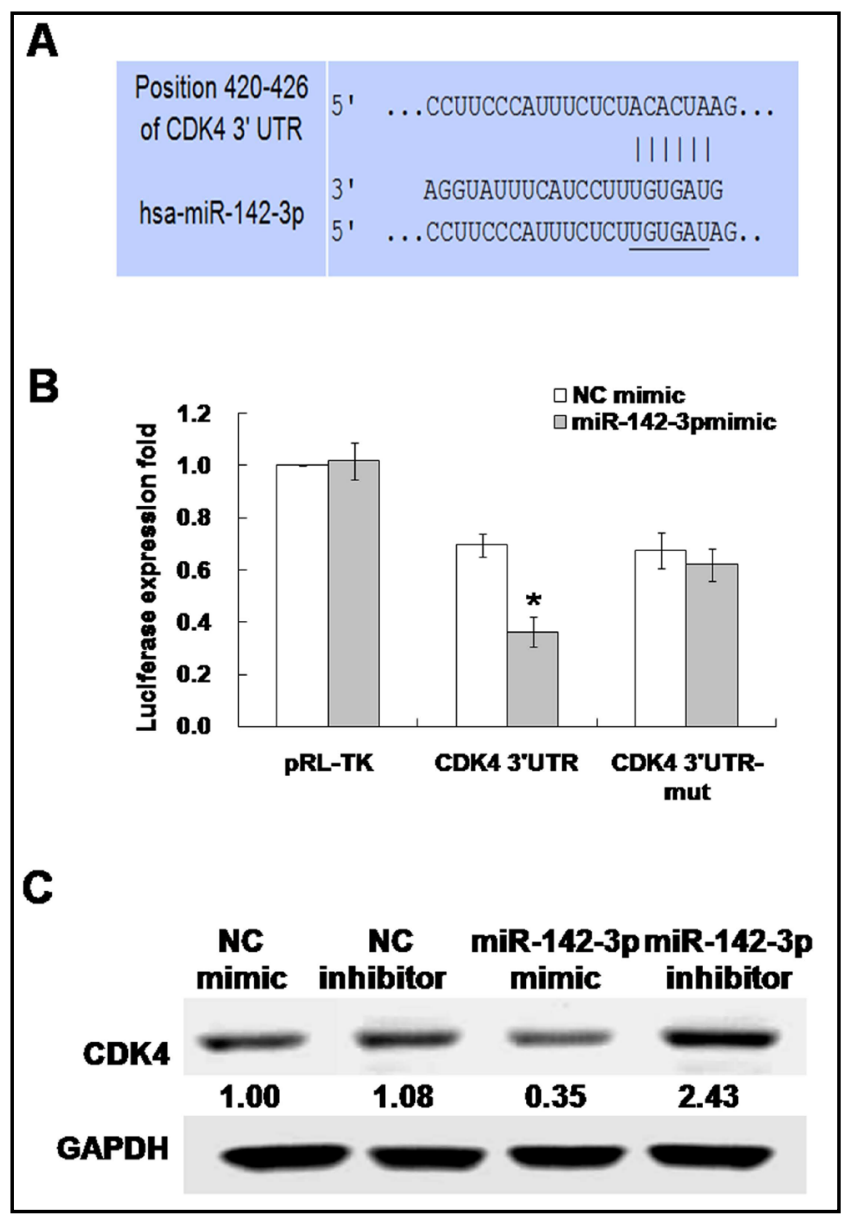

expression through the miR-142-3p binding sequence in its 3'-UTR. Furthermore, we found that transfection of the miR-142-3p mimic decreased CDK4 expression and that transfection of the miR-142-3p inhibitor increased CDK4 expression in HT29 cells at the protein (Fig. 4C), but not the mRNA, level (data not shown) suggesting that CDK4 expression may be inhibited by miR-142-3p at the posttranscriptional level. Together, these results show that miR-142$3 p$ may regulate the expression of endogenous CDK4 by directly targeting the 3'-UTR of its mRNA and, thus, that human CDK4 may be a new target of miR-142-3p.

\section{CDK4 knockdown induces cell cycle arrest}

To assess whether CDK4 expression down-regulation, like miR-142-3p expression up-regulation, results in CRC growth cessation, the effect CDK4 expression knockdown on cellular growth was examined. First, HT29 cells were transfected or not with the CDK4 siRNA or control siRNA. After 72 hours a dose-dependent knockdown of CDK4 was observed in the siRNA transfected cells (Fig. 5A). Through cell viability and cell cycle analyses, we subsequently found that the in vitro knockdown of CDK4 resulted in a repression of cell viability (Fig. 5B) and an induction of cell cycle arrest in HT29 cells (Fig. 5C). In order to confirm the effect of miR-142-3p on CDK4 expression, rescue experiments were performed for the cell viability and cell cycle assays. We found that exogenous over-expression of CDK4 in miR-142-3p mimic-transfected HT29 cells reversed the effect of the miR-142-3p mimic (Fig. 5B and 5C). Similar data were obtained with CDK4 siRNA transfected SW116 cells (data not shown). These results indicate that CDK4 is most likely involved in the induction of CRCderived cell cycle arrest by miR-142-3p. 
Fig. 5. CDK4 induces cell cycle arrest. A. Efficient siRNA-mediated inhibition of CDK4 expression. The expression of endogenous CDK4 was assessed 48 $\mathrm{h}$ after transfection with CDK4 siRNA or NC siRNA by Western blotting. GAPDH was used as an internal control. B. CDK4 knockdown reduces the viability of CRC-derived cells. Representative cell viability results are shown of HT29 cells transfected with CDK4 siRNA and NC siRNA, or not transfected cells. C. CDK4 knockdown induces cell cycle arrest in CRC-derived cells. Representative cell cycle results are shown of HT29 cells transfected with CDK4 siRNA, NC siRNA and, or not transfected cells. Columns, means of three independent experiments; bars, $\pm \mathrm{SD}$; ${ }^{*} \mathrm{P}<0.01 ;{ }^{* *} \mathrm{P}<0.001$.

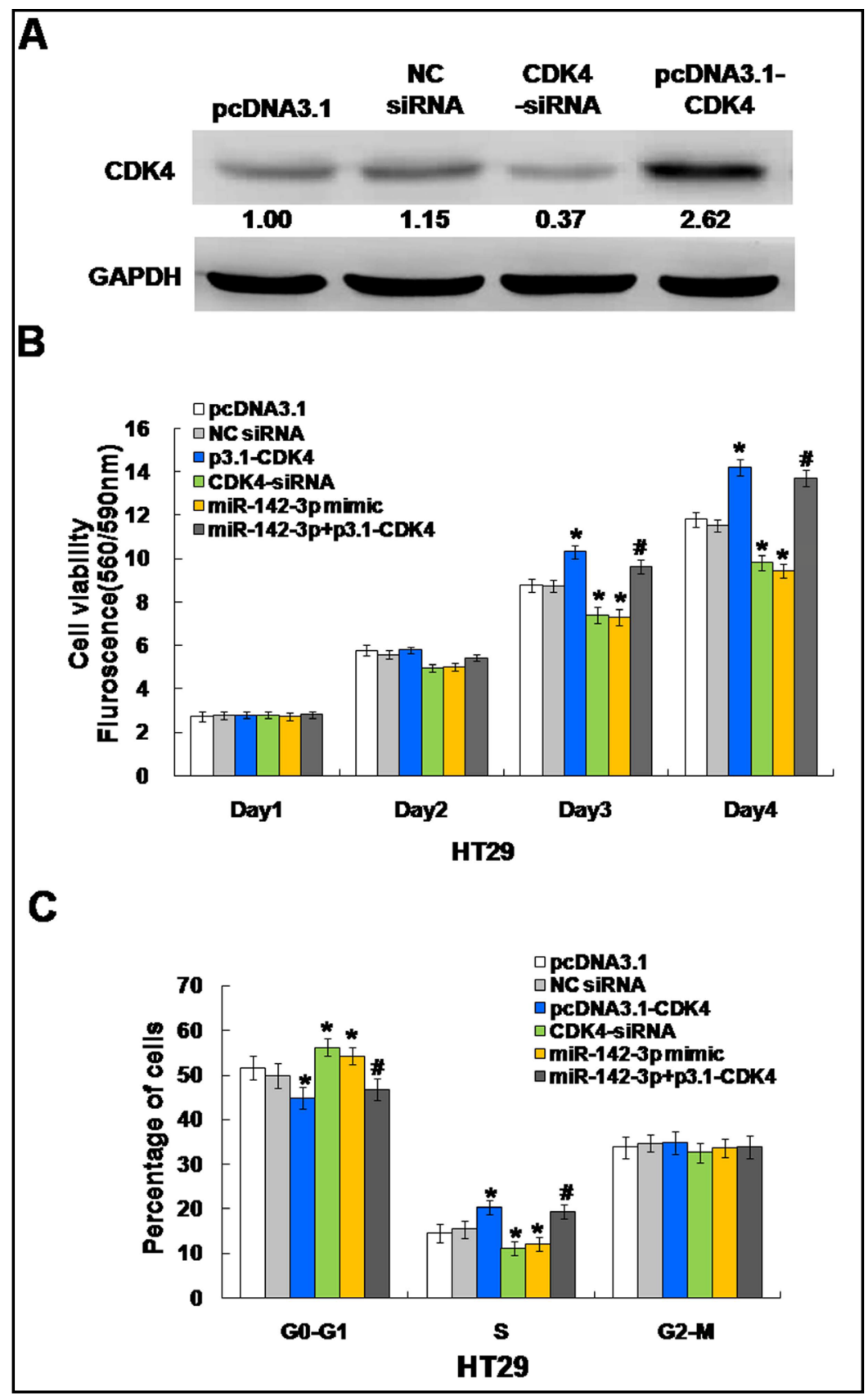

\section{Discussion}

In the past, miRNAs have been found to be frequently deregulated in CRC, and some miRNAs were found to be associated with particular clinicopathological features of CRC, such as metastasis, recurrence and prognosis [17-19]. Moreover, compelling evidence indicates that miRNAs may play important roles in CRC progression and may directly contribute to the proliferation, avoidance of apoptosis and metastasis of CRC [20, 21]. MiR-103 is an oncogene miRNA that promotes colorectal cancer proliferation and migration through downregulation of the tumor suppressor genes DICER and PTEN [22]; miR-204-5p acts as a tumor suppressor in colorectal cancer through inhibiting RAB22A [23]; miR-144 was markedly down-regulated in colorectal cancer and can inhibit the proliferation and migration of 


\section{Cellular Physiology Cell Physiol Biochem 2018;51:1969-1981 \begin{tabular}{ll|l} 
and Biochemistry & $\begin{array}{l}\text { DOl: 10.1159/000495721 } \\
\text { Published online: } 1 \text { December } 2018\end{array}$ & $\begin{array}{l}\text { O 2018 The Author(s). Published by S. Karger AG, Basel } \\
\text { www.karger.com/cpb }\end{array}$ \\
\cline { 2 - 3 }
\end{tabular} \\ Zhang et al.: miR-142-3p Targeting CDK4 in CRC}

colorectal cancer HCT116 cells [24]; the IL-6R/STAT3/miR-34a loop was necessary for EMT, invasion, and metastasis of CRC cell lines [25]; miR-378 expression was low in colon cancer tissues and cell lines and miR-378 not only inhibits the proliferation of colon cancer cells in vitro by inducing apoptosis, but also inhibits migration and invasion by inhibiting the EMT of colon cancer cells [26]; miR-153 was highly expressed in a cellular model of advanced stage colorectal cancer and increased colorectal cancer invasiveness and resistance to oxaliplatin and cisplatin [27]; miR-451 was over-expressed in multiple colorectal cancer tissues and might inhibit AMPK to activate mTORC1, which mediates FSCN1 expression and cancer cell progression [28].

miR-142 is expressed in many other tissues and displays a functional role in cancer, virus infection, inflammation and immune tolerance [29]. Most recent, miR-142-3p has been reported to be associated with several types of cancer. MiR-142-3p was significantly upregulated in renal cell carcinoma and miR-142-3p inhibitor could significantly suppressed cell migration and proliferation, and promoted cell apoptosis in 786-O and ACHN cells [30]; miR-142-3p was down-regulated in both cancer cell lines and cancer specimens and miR142-3p overexpression suppressed proliferation by leading cell cycle arrest in G2/M[31]; miR-142-3p was downregulated in hepatocellular carcinoma (HCC) tissues and the overexpression of miR-142-3p inhibited aerobic glycolysis and thus proliferation of HCC cells by targeting lactate dehydrogenase A (LDHA) [32]; miR-142-3p was significantly lower in ovarian cancer tissues and cell lines and Ectopic expression of miR-142-3p significantly inhibited the proliferation of ovarian cancer cells by targeting sirtuin 1 (SIRT1) and increased the sensitivity of SKOV3/DDP cells to cisplatin [33]; miR-142-3p was markedly downregulated in gastric cancer tissues and could inhibit the proliferation, invasion and migration of gastric cancer cells [34]; miR-142-3p inhibited proliferation and invasion in HeLa and SiHa cells by targeting frizzled 7 receptor [FZD7] [35]; miR-142-3p miR-142-3p downregulated MGMT expression and also sensitizedGlioblastoma multiforme [GBM] cells to alkylating drugs [36]; miR-142-3p overexpression increased PI3K, Akt, and mTOR phosphorylation by targeting High mobility group box-1 [HMGB1] in NSCLS cells [37]. According to CRC, three studies have suggested that miR-142-3p is involved in CRC development. On one hand, miR-142-3p promotes cellular invasion by activating RAC1 in colorectal cancer cells [38]. On another hand, miR-142-3p functions as a tumor suppressor by targeting CD133, ABCG2, and Lgr5 in colon cancer cells [39]. Moreover, downregulation of plasma miR-142-3p was reported in CRC patients [40]. Thus, the role of miR-142-3p on CRC progression is unclear. In this study, miR-142-3p was indentified to play a role in cell growth and apoptosis in CRC.

Based on an in silico MiRanda search, CDK4 was predicted to be a target of miR-142-3p. CDK4 is known to be expressed in nearly all proliferating cells and to be able to promote cell cycle progression [41]. CDK4 has been reported to be regulated by several miRNAs, including miR-206, miR-506, miR-138, miR-124, miR-545 and miR-302 [42-47]. We, for the first time, identified CDK4 as a target of miR-142-3p in CRC, which may provide new insights into the mechanisms underlying its tumorigenesis. In addition, cell cycle progression is known to be regulated by a family of cyclin-dependent kinases (CDKs) and their activating partners (Cyclins). The G1/S phase cell cycle transition is regulated primarily by D-type Cyclins (D1, D2 or D3) in complex with CDK4/CDK6, and E-type Cyclins (E1 or E2) in complex with CDK2. These complexes cooperate in phosphorylating and in preventing Rb binding to $\mathrm{E} 2 \mathrm{~F}$, thus activating E2F-mediated transcription and driving cells from the G1 into the S phase of the cell cycle [48]. Whether the CDK/pRb/E2F pathway is also involved in the miR-142-3pmediated induction of cell cycle arrest in CRC cells requires further investigation.

\section{Conclusion}

In conclusion, we here provide evidence that low miR-142-3p expression contributes to cell viability and cell cycle progression in CRC via direct binding to the CDK4 3'-UTR. As such, miR-142-3p may act as a tumor suppressor and as a miRNA-based CRC therapeutic agent.

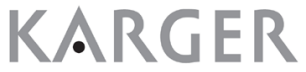




\section{Cellular Physiology Cell Physiol Biochem 2018;51:1969-1981 \begin{tabular}{ll|l} 
and Biochemistry & $\begin{array}{l}\text { DOI: 10.1159/000495721 } \\
\text { Published online: 1 December } 2018\end{array}$ & $\begin{array}{l}\text { (c) } 2018 \text { The Author(s). Published by S. Karger AG, Basel } \\
\text { www.karger.com/cpb }\end{array}$
\end{tabular} \\ Zhang et al.: miR-142-3p Targeting CDK4 in CRC}

\section{Acknowledgements}

This work was supported by the National Natural Science Fund from the National Natural Science Foundation of China (81402367); Clinical Capability Construction Project for Liaoning Provincial Hospitals (LNCCC-D44-2015); Liaoning BaiQianWan Talents Program [2017] No.B44; Liaoning clinical research center for colorectal cancer(grant nos.2015225005).

\section{Disclosure Statement}

The authors declare that they have no competing interests.

\section{References}

1 Parkin DM, Bray F, Ferlay J, Pisani P: Global cancer statistics, 2002. CA Cancer J Clin 2005;5:74-108.

2 Fakih MG: Metastatic colorectal cancer: current state and future directions. J Clin Oncol 2015;33:18091824.

3 Del Vescovo V, Grasso M, Barbareschi M, Denti MA: MicroRNAs as lung cancer biomarkers. World J Clin Oncol 2014;5:604-620.

4 Bartel DP: MicroRNAs: genomics, biogenesis, mechanism, and function. Cell 2004;116:281-297.

5 Schickel R, Boyerinas B, Park SM, Peter ME: MicroRNAs: key players in the immune system, differentiation, tumorigenesis and cell death. Oncogene 2008;27:5959-5974.

6 Cellura D, Pickard K, Quaratino S, Parker H, Strefford JC, Thomas GJ, Mitter R, Mirnezami AH, Peake NJ: miR-19-mediated inhibition of transglutaminase-2 leads to enhanced invasion and metastasis in colorectal cancer. Mol Cancer Res 2015;13:1095-1105.

7 Zhang W, Zou C, Pan L, Xu Y, Qi W, Ma G, Hou Y, Jiang P: MicroRNA-140-5p inhibits the progression of colorectal cancer by targeting VEGFA. Cell Physiol Biochem 2015;37:1123-1133.

$>8$ Xu K, Liu X, Mao X, Xue L, Wang R, Chen L, Chu X: MicroRNA-149 suppresses colorectal cancer cell migration and invasion by directly targeting forkhead box transcription factor FOXM1. Cell Physiol Biochem 2015;35:499-515.

-9 Zhang L, Pickard K, Jenei V, Bullock MD, Bruce A, Mitter R, Kelly G, Paraskeva C, Strefford J, Primrose J, Thomas GJ, Packham G, Mirnezami AH: miR-153 supports colorectal cancer progression via pleiotropic effects that enhance invasion and chemotherapeutic resistance. Cancer Res 2013;73:6435-6447.

10 Zhang M, Wu W, Gao M, Zhang J, Ding X, Zhu R, Chen H, Fei Z: Coactivator-associated arginine methyltransferase 1 promotes cell growth and is targeted by microRNA-195-5p in human colorectal cancer. Tumour Biol 2017;39:1010428317694305.

11 Fang Y, Sun B, Xiang J, Chen Z: MiR-301a promotes colorectal cancer cell growth and invasion by directly targeting SOCS6. Cell Physiol Biochem 2015;35:227-236.

-12 Shrestha A, Mukhametshina RT, Taghizadeh S, Vásquez-Pacheco E, Cabrera-Fuentes H, Rizvanov A, Mari B, Carraro G, Bellusci S: MicroRNA-142 is a multifaceted regulator in organogenesis, homeostasis, and disease. Dev Dyn 2017;246:285-290.

-13 Jin Y, Chen D, Cabay RJ, Wang A, Crowe DL, Zhou X: Role of microRNA-138 as a potential tumor suppressor in head and neck squamous cell carcinoma. Int Rev Cell Mol Biol 2013;303:357-385.

14 Nohata N, Hanazawa T, Enokida H, Seki N: microRNA-1/133a and microRNA-206/133b clusters: dysregulation and functional roles in human cancers. Oncotarget 2012;3:9-21.

15 Sharma T, Hamilton R, Mandal CC: miR-214: a potential biomarker and therapeutic for different cancers. Future Oncol 2015;11:349-363.

16 Gopalan V, Smith RA, Lam AK: Downregulation of microRNA-498 in colorectal cancers and its cellular effects. Exp Cell Res 2015;330:423-428.

17 Thomas J, Ohtsuka M, Pichler M, Ling H: MicroRNAs: Clinical Relevance in Colorectal Cancer. Int J Mol Sci 2015;16:28063-28076. 


\section{Cellular Physiology Cell Physiol Biochem 2018;51:1969-1981 \begin{tabular}{ll|l} 
DOI: 10.1159/000495721 & O 2018 The Author(s). Published by S. Karger AG, Basel \\
www.karger.com/cpb
\end{tabular} \\ Zhang et al.: miR-142-3p Targeting CDK4 in CRC}

18 Clancy C, Joyce MR, Kerin MJ: The use of circulating microRNAs as diagnostic biomarkers in colorectal cancer. Cancer Biomark 2015;15:103-113

19 Muhammad S, Kaur K, Huang R, Zhang Q, Kaur P, Yazdani HO, Bilal MU, Zheng J, Zheng L, Wang XS: MicroRNAs in colorectal cancer: role in metastasis and clinical perspectives. World J Gastroenterol 2014;20:17011-17019.

20 Thomas J, Ohtsuka M, Pichler M, Ling H: MicroRNAs: Clinical Relevance in Colorectal Cancer. Int J Mol Sci 2015;16:28063-28076.

21 Muhammad S, Kaur K, Huang R, Zhang Q, Kaur P, Yazdani HO, Bilal MU, Zheng J, Zheng L, Wang XS: MicroRNAs in colorectal cancer: role in metastasis and clinical perspectives. World J Gastroenterol 2014;20:17011-17019.

22 Geng L, Sun B, Gao B, Wang Z, Quan C, Wei F, Fang XD: MicroRNA-103 promotes colorectal cancer by targeting tumor suppressor DICER and PTEN. Int J Mol Sci 2014;15:8458-8472.

-23 Yin Y, Zhang B, Wang W, Fei B, Quan C, Zhang J, Song M, Bian Z, Wang Q Ni S, Hu Y, Mao Y, Zhou L, Wang Y, Yu J, Du X, Hua D, Huang Z: MiR-204-5p inhibits proliferation and invasion and enhances chemotherapeutic sensitivity of colorectal cancer cells by downregulating RAB22A. Clin Cancer Res 2014;20:6187-6199.

24 Xiao R, Li C, Chai B: miRNA-144 suppresses proliferation and migration of colorectal cancer cells through GSPT1. Biomed Pharmacother 2015;74:138-144.

-25 Rokavec M, Öner MG, Li H, Jackstadt R, Jiang L, Lodygin D, Kaller M, Horst D, Ziegler PK, Schwitalla S, SlottaHuspenina J, Bader FG, Greten FR, Hermeking H: IL-6R/STAT3/miR-34a feedback loop promotes EMTmediated colorectal cancer invasion and metastasis. J Clin Invest 2014;124:1853-1867

26 Zeng M, Zhu L, Li L, Kang C: MiR-378 suppresses the proliferation, migration and invasion of colon cancer cells by inhibiting SDAD1. Cell Mol Biol Lett 2017;22:12.

27 Zhang L, Pickard K, Jenei V, Bullock MD, Bruce A, Mitter R, Kelly G, Paraskeva C, Strefford J, Primrose J, Thomas GJ, Packham G, Mirnezami AH: MiR-153 supports colorectal cancer progression via pleiotropic effects that enhance invasion and chemotherapeutic resistance. Cancer Res 2013;73:6435-6447.

28 Chen MB, Wei MX, Han JY, Wu XY, Li C, Wang J, Shen W, Lu PH: MicroRNA-451 regulates AMPK/mTORC1 signaling and fascin1 expression in HT-29 colorectal cancer. Cell Signal 2014;26:102-109.

-29 Shrestha A, Mukhametshina RT, Taghizadeh S, Vásquez-Pacheco E, Cabrera-Fuentes H, Rizvanov A, Mari B, Carraro G, Bellusci S: MicroRNA-142 is a multifaceted regulator in organogenesis, homeostasis and disease. Dev Dyn 2017; 246:285-290.

-30 Li Y, Chen D, Jin LU, Liu J, Li Y, Su Z, Qi Z, Shi M, Jiang Z, Yang S, Gui Y, Mao X, Wu X, Lai Y: Oncogenic microRNA-142-3p is associated with cellular migration, proliferation and apoptosis in renal cell carcinoma. Oncol Lett 2016;11:1235-1241.

31 Cao XC, Yu Y, Hou LK, Sun XH, Ge J, Zhang B, Wang X: miR-142-3p inhibits cancer cell proliferation by targeting CDC25C. Cell Prolif 2016;49:58-68.

-32 Hua S, Liu C, Liu L, Wu D: miR-142-3p inhibits aerobic glycolysis and cell proliferation in hepatocellular carcinoma via targeting LDHA. Biochem Biophys Res Commun 2018;496:947-954.

-33 Gao J, Wu N, Liu X, Xia Y, Chen Y, Li S, Deng Z: MicroRNA-142-3p inhibits cell proliferation and chemoresistance in ovarian cancer via targeting sirtuin 1. Exp Ther Med 2018;15:5205-5214.

-34 Wang Y, Cao Z, Wang L, Liu S, Cai J: Downregulation of miR-142-3p and its tumor suppressor role in gastric cancer. Oncol Lett 2018;15:8172-8180.

-35 Deng B, Zhang Y, Zhang S, Wen F, Miao Y, Guo K: MicroRNA-142-3p inhibits cell proliferation and invasion of cervical cancer cells by targeting FZD7. Tumour Biol 2015;36:8065-8073.

-36 Lee YY, Yarmishyn AA, Wang ML, Chen HY, Chiou SH, Yang YP, Lin CF, Huang PI, Chen YW, Ma HI, Chen MT: MiR-142-3p is involved in regulation of MGMT expression in glioblastoma cells. Cancer Manag Res 2018;10:775-785.

37 Chen Y, Zhou X, Qiao J, Bao A: MiR-142-3p overexpression increases chemo-sensitivity of NSCLC by Inhibiting HMGB1 mediated autophagy. Cell Physiol Biochem 2017;41:1370-1382.

-38 Gao X, Xu W, Lu T, Zhou J, Ge X, Hua D: MicroRNA-142-3p Promotes Cellular Invasion of Colorectal Cancer Cells by Activation of RAC1. Technol Cancer Res Treat 2018;17:1533033818790508.

-39 Shen WW, Zeng Z, Zhu WX, Fu GH: MiR-142-3p functions as a tumor suppressor by targeting CD133, ABCG2, and Lgr5 in colon cancer cells. J Mol Med (Berl) 2013;91:989-1000. 


\section{Cellular Physiology Cell Physiol Biochem 2018:51:1969-1981 \begin{tabular}{ll|l} 
and Biochemistry & Dol: 10.1159/000495721 \\
Published online: T December 2018 & $\begin{array}{l}\text { O } 2018 \text { The Author(s). Published by S. Karger AG, Basel } \\
\text { www.karger.com/cpb }\end{array}$ \\
\hline
\end{tabular}}

Zhang et al.: miR-142-3p Targeting CDK4 in CRC

40 Ghanbari R, Mosakhani N, Asadi J, Nouraee N, Mowla SJ, Yazdani Y, Mohamadkhani A, Poustchi H, Knuutila S, Malekzadeh R: Downregulation of Plasma MiR-142-3p and MiR-26a-5p in Patients With Colorectal Carcinoma. Iran J Cancer Prev 2015;8:e2329.

41 Grillo M, Bott MJ, Khandke N, McGinnis JP, Miranda M, Meyyappan M, Rosfjord EC, Rabindran SK: Validation of cyclin D1/CDK4 as an anticancer drug target in MCF-7 breast cancer cells: effect of regulated overexpression of cyclin D1 and siRNA-mediated inhibition of endogenous cyclin D1 and CDK4 expression. Breast Cancer Res Treat 2006;95:185-194.

-42 Georgantas RW 3rd, Streicher K, Luo X, Greenlees L, Zhu W, Liu Z, Brohawn P, Morehouse C, Higgs BW, Richman L, Jallal B, Yao Y, Ranade K: MicroRNA-206 induces G1 arrest in melanoma by inhibition of CDK4 and Cyclin D. Pigment Cell Melanoma Res 2014;27:275-286.

43 Liu G, Sun Y, Ji P, Li X, Cogdell D, Yang D, Parker Kerrigan BC, Shmulevich I, Chen K, Sood AK, Xue F, Zhang W: MiR-506 suppresses proliferation and induces senescence by directly targeting the CDK4/6-FOXM1 axis in ovarian cancer. J Pathol 2014;233:308-318.

44 Qiu S, Huang D, Yin D, Li F, Li X, Kung HF, Peng Y: Suppression of tumorigenicity by microRNA-138 through inhibition of EZH2-CDK4/6-pRb-E2F1 signal loop in glioblastoma multiforme. Biochim Biophys Acta 2013;1832:1697-1707.

45 Feng T, Xu D, Tu C, Li W, Ning Y, Ding J, Wang S, Yuan L, Xu N, Qian K, Wang Y, Qi C: miR-124 inhibits cell proliferation in breast cancer through downregulation of CDK4 Tumour Biol 2015;36:5987-5997.

46 Deng X, Ma L, Wu M, Zhang G, Jin C, Guo Y, Liu R: miR-124 radiosensitizes human glioma cells by targeting CDK4. J Neurooncol 2013;114:263-274.

47 Du B, Wang Z, Zhang X, Feng S, Wang G, He J, Zhang B: MicroRNA-545 suppresses cell proliferation by targeting cyclin D1 and CDK4 in lung cancer cells. PLoS One 2014;9:e88022.

48 Lin SL, Chang DC, Ying SY, Leu D, Wu DT: MicroRNA miR-302 inhibits the tumorigenecity of human pluripotent stem cells by coordinate suppression of the CDK2 and CDK4/ 6 cell cycle pathways. Cancer Res 2010;70:9473-9482. 